\title{
EFFECT OF POSITIVE END-EXPIRATORY PRESSURE ON LUNG MECHANICS DURING ANAESTHESIA IN DOGS
}

\author{
F.G. DOUGLAS AND D.C. FinLAYSON
}

REDUCTION IN LUNG COMPLIANCE has commonly been reported in patients with otherwise normal lungs undergoing general anaesthesia. ${ }^{1-3}$ The cause of the decreased compliance is not clearly defined, but suppression of normal periodic sighing and consequent increase in surface tension of lung has been suggested as the mechanism responsible. ${ }^{4}$ However, hyperinflation of lung is not always successful in restoring compliance in this circumstance. ${ }^{2}$ Alternatively, anaesthesia has been shown to result in diminution of functional residual capacity (FRC), ${ }^{5}$ and it is well established that breathing at reduced lung volume leads to increase in static elastic recoil of lung; ${ }^{6}$ indeed, Westbrook, et al. ${ }^{5}$ have recently presented evidence to suggest that just such a sequence of events is responsible for the small lung compliance values during anaesthesia. They further suggested that maintenance of a larger lung volume, as by the application of positive end-expiratory pressure, might prevent the reduction in lung compliance.

Therefore, in the present study we used anaesthetized dogs, in which frequent measurements of FRC were possbile, to determine whether we could maintain an increased FRC over a prolonged interval by application of positive end-expiratory pressure and whether we could in this way prevent the diminution in lung compliance which has been clearly demonstrated during anaesthesia when endexpiratory pressure is zero. ${ }^{4,7}$ In addition to positive end-expiratory pressure, we used controlled mechanical ventilation to maintain normal alveolar ventilation and to avoid possible anaesthesia-induced shallow breathing, which could by itself diminish compliance. ${ }^{7}$ We then made sequential measurements of FRC and of lung compliance during one hour of this continuous positive pressure ventilation (CPPV).

CPPV in the present context means that airway pressure was positive throughout the breathing cycle. This was achieved during expiratory relaxation by immersion of expired gas line in water (positive end-expiratory pressure), and during inspiration the airway pressure was increased further by positive pressure inflation of lung from a mechanical ventilator.

\section{Methods}

Seven mongrel dogs were studied, All were supine and each dog was prepared

F.G. Douglas, M.D., F.R.C.P.(C), Department of Medicine; D.C. Finlayson, M.D., F.R.C.P.(C), Department of Anaesthesia, St. Michael's Hospital and the University of Toronto, Toronto, Canada.

Mailing address: F.G. Douglas, M.D., St. Michael's Hospital, 30 Bond Street, Toronto, Ontario M5B IW8. 
as follows: anaesthesia was induced with intravenous sodium pentobarbital, 25 $\mathrm{mg} / \mathrm{kg}$; tracheostomy was performed, a femoral artery was cannulated, and an oesophageal balloon was inserted. The balloon was made of thin latex, $10 \mathrm{~cm}$ long with a $0.5 \mathrm{~cm}$ perimeter, and was sealed over a polyethylene tube (.063"i.d.). The balloon was positioned by passage into the stomach or lower oesophagus, where positive or slightly subatmospheric pressures were recorded, and slowly withdrawn until no further increase in subatmospheric pressure was noted. Balloon volume was maintained at an amount found to produce volume independent pressure measurements. We judged pressure measurements to be free of artifacts when transpulmonary pressure $\left(\mathrm{P}_{\mathrm{tp}}\right)$ remained constant during respiratory efforts against the occluded airway.

The dog was entirely enclosed in a whole-body plethysmograph (250-litre, ${ }_{38}^{3}$-inch Plexiglas box) and the tracheostomy tube was connected through a port in the box to room air. The inside of the chamber was open to atmosphere at all times except during measurements of FRC, as noted below. The lungs were then hyperinflated twice by the manual introduction into airway, from a calibrated 1.5-litre air-containing syringe, of a volume sufficient to produce a $\mathrm{P}_{\mathrm{tp}}$ of $30 \mathrm{~cm}$ $\mathrm{H}_{2} \mathrm{O}$. $\mathrm{P}_{\mathrm{tp}}$ was measured by referring oesophageal to airway pressure with a Statham PM 5 transducer.

Immediately thereafter the following control measurements were obtained. During tidal breathing, transpulmonary pressure, airway flow and tidal volume were recorded with a Mingograph 800 multichannel machine and subsequently used to calculate dynamic lung compliance $\left(\mathbf{C}_{\mathrm{DrN}}\right)$ as follows: simultaneous volume and transpulmonary pressure changes were measured at points of zero air flow for each of approximately six breaths; compliance for each breath was then determined as the ratio of this volume change to its $P_{t p}$ change, the average of these ratios being reported as the value for $C_{D r x}$. In addition, the airway was occluded at end-tidal inspiration for a time sufficient to obtain a $P_{r p}$ plateau to be used for calculation of static lung compliance $\left(\mathrm{C}_{\mathrm{STAT}}\right)$. Thus $\mathrm{C}_{\mathrm{ST}_{\mathrm{T}} \mathrm{T}}$ differs from $\mathrm{C}_{\mathrm{DXX}}$ in that the $\mathrm{P}_{\mathrm{tp}}$ values used for its calculation were obtained under true static conditions rather than at instants of no flow during tidal breathing. FRC was then measured after airway occlusion at end-tidal expiration by the plethysmographic technique of DuBois, et al., ${ }^{8}$ modified for dogs as we have previously described. ${ }^{7}$

Mechanical ventilation was then begun with CPPV using the Engström constant tidal volume ventilator. Positive end-expiratory airway pressure of $5 \mathrm{~cm} \mathrm{H}_{2} \mathrm{O}$ was achieved by immersing the expired air line in water. Respiratory rate was set at 20 breaths per minute for each dog and tidal volume was adjusted to achieve an arterial carbon dioxide tension $\left(\mathrm{Pa}_{\mathrm{CO}_{2}}\right)$ within the expected normal range ${ }^{9}$ by monitoring end-tidal carbon dioxide concentration with an infrared analyzer (Godart-Statham Capnograph). Intravenous sodium pentobarbital $50 \mathrm{mg}$ was repeated at half-hour intervals to prevent spontaneous respiratory efforts. With this regimen no further ventilator adjustments were required and complete control of ventilation was achieved in all dogs. All animals breathed room air throughout. Body temperature was monitored with a rectal thermometer and was maintained at $37^{\circ} \mathrm{C}$ by intravenous infusion of normal saline through a heating coil. No hyperinflations were given except as specifically noted. 
DOUGLAS \& FINLAYSON: LUNG MECHANICS DURING PEEP

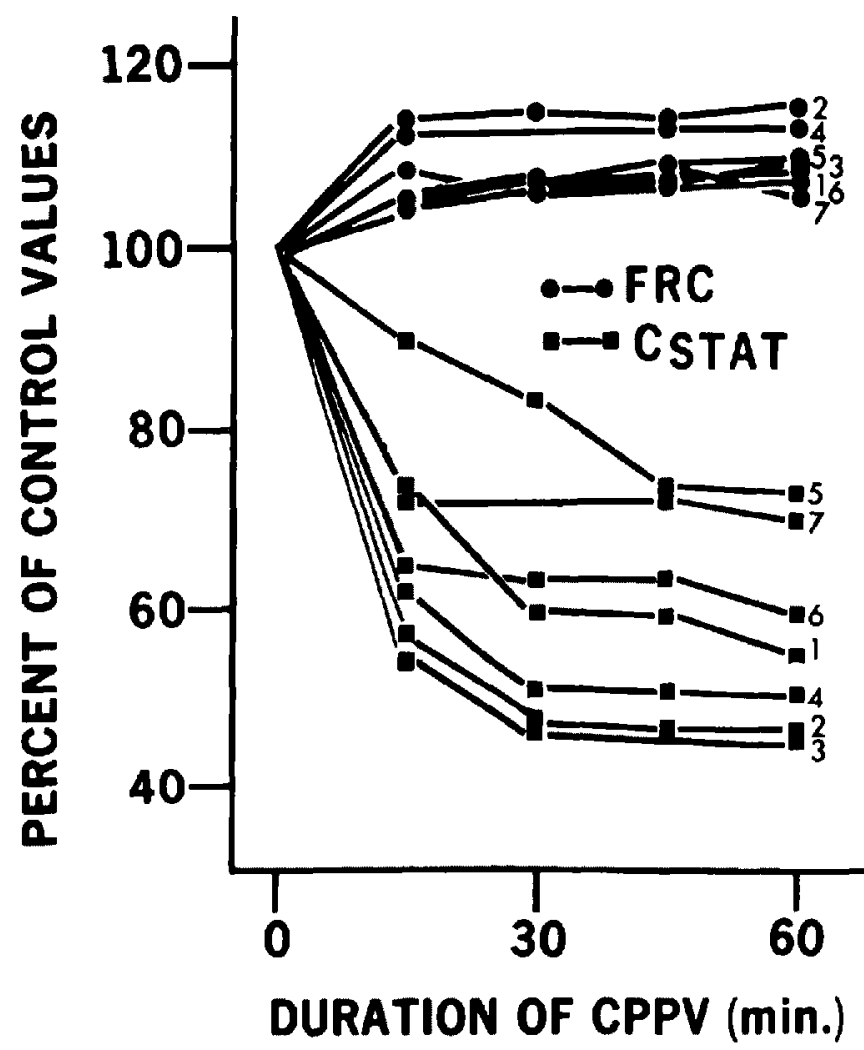

Figune 1. Functional residual capacity (FRC) and static lung compliance $\left(\mathrm{C}_{\text {STAT }}\right.$ ) values obtained during continuous positive pressure ventilation (CPPV). Numbers to the right designate individual dogs.

CPPV was continued for one hour during which we determined $\mathrm{C}_{\mathrm{Drx}}$ and $\mathrm{FRC}$ at the end-expiratory level (determined by the positive airway pressure) at 15-minute intervals. Arterial blood samples were taken for respiratory gas analysis. After one hour of CPPV the lungs were hyperinflated twice to $\mathrm{P}_{\mathrm{tp}}$ of $30 \mathrm{~cm} \mathrm{H}_{2} \mathrm{O}$ and lung compliance measurements were made immediately thereafter, again at $5 \mathrm{~cm}$ $\mathrm{H}_{2} \mathrm{O}$ positive end-expiratory pressure.

\section{ResuLts}

Figure I shows that FRC was increased in each dog following the initiation of CPPV, but there were no important changes in this measurement thereafter. However, it may also be seen that, over the same time interval, $\mathrm{C}_{\mathrm{STAT}}$ was diminished in all dogs and these reductions were marked in most.

Table I shows the actual values for FRC obtained in the control period and compares them with those measured at the beginning and end of CPPV.

Table II compares the initial control values for $\mathrm{C}_{\mathrm{STAT}}$ with those computed after one hour of CPPV and after hyperinflation (artificial sighs). It may be seen that a 
TABLE I

Functional Residual Capacity (FRC) Measurements

\begin{tabular}{ccccc}
\hline \hline & & \multicolumn{2}{c}{ FRC (ml/kg) } \\
\cline { 3 - 5 } Dog & $\begin{array}{c}\text { Weight } \\
\text { kg }\end{array}$ & Control & $\begin{array}{c}\text { First } \\
\text { during } \\
\text { CPPV }\end{array}$ & $\begin{array}{c}\text { After } \\
\text { one hour } \\
\text { of CPPV }\end{array}$ \\
\hline 1 & 11.0 & 34.0 & 41.0 & 39.1 \\
2 & 9.3 & 45.5 & 54.0 & 54.2 \\
3 & 14.3 & 39.6 & 45.2 & 45.9 \\
4 & 15.9 & 37.8 & 44.6 & 44.6 \\
5 & 14.1 & 39.4 & 45.1 & 45.3 \\
6 & 16.7 & 41.8 & 48.8 & 47.7 \\
7 & 20.1 & 33.5 & 38.0 & 38.9 \\
Mean & 14.4 & 38.8 & $45.2^{*}$ & $45.1^{*}$ \\
SD & 1.3 & 1.59 & 1.95 & 1.98 \\
\hline
\end{tabular}

*Both FRC measurements during CPPV are significantly larger than control ( $p<0.001$ in each case).

TABLE II

Lung Compliance Changes

\begin{tabular}{|c|c|c|c|c|c|c|}
\hline \multirow[b]{3}{*}{ Dog* } & \multicolumn{6}{|c|}{ Lung compliance $\left(\mathrm{ml} / \mathrm{cmH}_{2} \mathrm{O} / \mathrm{kg}\right)$} \\
\hline & \multicolumn{2}{|c|}{ Control } & \multicolumn{2}{|c|}{$\begin{array}{l}\text { After one hour } \\
\text { of CPPV }\end{array}$} & \multicolumn{2}{|c|}{$\begin{array}{c}\text { After } \\
\text { hyperinflation }\end{array}$} \\
\hline & Static & Dynamic & Static & Dynamic & Static & Dynamic \\
\hline $\begin{array}{l}1 \\
2 \\
3 \\
4 \\
5 \\
6 \\
7\end{array}$ & $\begin{array}{l}3.8 \\
3.5 \\
4.7 \\
3.8 \\
4.2 \\
4.5 \\
3.0\end{array}$ & $\begin{array}{l}3.8 \\
3.6 \\
4.4 \\
3.5 \\
4.1 \\
4.1 \\
3.1\end{array}$ & $\begin{array}{l}2.5 \\
2.1 \\
2.4 \\
2.1 \\
3.4 \\
2.8 \\
2.5\end{array}$ & $\begin{array}{l}2.1 \\
1.8 \\
2.0 \\
1.7 \\
3.1 \\
2.5 \\
2.3\end{array}$ & $\begin{array}{l}3.7 \\
3.6 \\
3.7 \\
3.8 \\
4.3 \\
4.5 \\
3.0\end{array}$ & $\begin{array}{l}3.5 \\
3.0 \\
4.2 \\
3.2 \\
4.0 \\
4.1 \\
3.0\end{array}$ \\
\hline $\begin{array}{l}\text { Mean } \\
\text { SD }\end{array}$ & $\begin{array}{l}3.9 \\
0.22\end{array}$ & & $\begin{array}{l}2.5 \dagger \\
0.22\end{array}$ & & $\begin{array}{l}3.9 \\
0.22\end{array}$ & \\
\hline
\end{tabular}

*Weight for each dog is listed in Table I.

tValues after one hour of CPPV are significantly smaller than both the control and posthyperinflation values ( $p<0.01$ in each case).

significant reduction occurred in $\mathrm{C}_{\mathrm{STAT}}$ during $\mathrm{CPPV}(\mathrm{p}<0.01)$ but that the hyperinfiations resulted in complete reversal back to the control observations. In all dogs, the $\mathrm{C}_{\mathrm{DYN}}$ measurements compared closely with their respective $\mathrm{C}_{\mathrm{STAT}}$ values.

Table III compares the arterial blood gases produced by the original ventilator settings with those found after one hour of mechanical ventilation. Only small and inconsistent changes were seen.

Student's $t$ test for paired observations was used for all the statistical analyses.

Discussion

In common with previous work, ${ }^{10}$ the present experiment has shown that positive end-expiratory pressure is effective in increasing FRC and, in addition, we found 
TABLE III

Arterial Blood Gases During CPPV

(room air)

\begin{tabular}{cccccc}
\hline \hline & $\begin{array}{c}\text { Arterial oxygen tension } \\
(\mathrm{mm} \mathrm{Hg})\end{array}$ & & \multicolumn{2}{c}{$\begin{array}{c}\text { Arterial carbon dioxide } \\
\text { tension }(\mathrm{mm} \mathbf{H g})\end{array}$} \\
\cline { 2 - 4 } \cline { 5 - 6 } Dog & Initial & Final & & Initial & Final \\
\hline 1 & 93 & 100 & & 40 & 40 \\
2 & 79 & 72 & 38 & 40 \\
3 & 93 & 100 & & 41 & 31 \\
4 & 78 & 79 & & 40 & 36 \\
5 & 95 & 98 & 33 & 33 \\
6 & 71 & 71 & 36 & 37 \\
7 & 76 & 78 & 37 & 35 \\
\hline
\end{tabular}

that the increase can be consistently maintained over a prolonged interval. However, it might still be questioned whether the amount of positive end-expiratory pressure we applied was sufficient to restore FRC to pre-anaesthesia levels and to entirely prevent "low lung volume breathing". Gillespie and Hyatt ${ }^{11}$ measured FRC in a group of six specially trained dogs while unanaesthetized and breathing spontaneously and found, in the supine position, an average value of $48.1 \mathrm{ml} / \mathrm{kg}$ (SD 1.27). Using Student's $t$ test for unpaired observations, we have tested Gillespie and Hyatt's results against our FRC measurements made during CPPV and have found that the difference is not statistically significant. That is, the amount of positive airway pressure we applied was sufficient to restore and maintain endexpiratory volume at the expected level for awake spontaneously breathing dogs in the same posture.

However, despite preservation of lung volume, we observed marked diminution in lung compliance. The reduction was equally large in both $\mathrm{C}_{\mathrm{STAT}}$ and $\mathrm{C}_{\mathrm{DTY}}$. Since $\mathrm{C}_{\mathrm{STAT}}$ reflects the static volume-pressure properties of lung it is clear that these must have been altered during CPPV. $\mathrm{C}_{\mathrm{DrX}}$ assesses the volume-pressure relationships too, but is also influenced by abnormally large regional inequalities in the flow resistance. ${ }^{12}$ Our $\mathrm{C}_{\mathrm{Dr}}$ measurements closely matched their respective $\mathrm{C}_{\mathrm{STAT}}$ values and we therefore conclude that static volume-pressure changes alone were responsible for the compliance reduction.

Reduction in our $\mathrm{C}_{\mathrm{STAT}}$ values would be expected if the elastic recoil forces of lung were increased or if overall lung volume were diminished, and $\mathrm{C}_{\mathrm{STAT}}$ could also be influenced by the size of the volume excursion over which the measurement is made. ${ }^{13}$ However, during CPPV lung volume remained constant (at least there were no detectable changes in FRC), and all compliance measurements were made over the same volume excursion (i.e., the tidal volume range). Therefore, elastic recoil was the main variable in our $\mathrm{C}_{\mathrm{STAT}}$ measurement and must have increased during CPPV.

We found marked reversibility in the compliance reductions following hyperinflations. Indeed, such a response to hyperinflation has been well described as a consequence of reversible increase in lung surface tension due to the absence of normal periodic sighing. ${ }^{1,4}$ Since our dogs were not sighed during CPPV it is therefore possible that such a mechanism accounts for our findings.

On the other hand, the magnitude of diminution in compliance that we observed 
here is entirely comparable to what $\mathrm{we}^{7}$ and others ${ }^{4}$ have measured in anaesthetized dogs undergoing ventilation with zero end-expiratory pressure. We might have anticipated that the use of positive end-expiratory pressure and consequent prevention of low lung volume breathing, as well as maintenance of normal alveolar ventilation, would have at least minimized reduction of compliance even in the absence of sighs. The recent observations of Froese and Bryan have possible relevance to our findings. ${ }^{1+}$ These workers found evidence in anaesthetized and paralyzed subjects to indicate that the increase in FRC with positive end-expiratory pressure is not uniform; specifically, lung zones adjacent to the least compliant portions of chest wall undergo little increase in regional volume even though overall lung volume is enlarged. If our deeply anaesthetized dogs behaved similarly, at least part of the compliance reduction that we observed might have occurred in areas of lung that remained at small regional FRC despite our finding of well preserved overall lung volume.

Thus we have shown in dogs that during anaesthesia, even when FRC was maintained by positive end-expiratory pressure at a value closely approximating that expected in the awake spontaneously breathing state, large reduction in lung compliance occurred, reversible by hyperinflation. The reductions in computed values of lung compliance were due to altered static volume-pressure relationships of lung. Since the changes were reversed following hyperinflation, it is possible that absence of periodic sighing was their cause, but regional low lung volume ventilation may also have been an important factor.

Clinical implications from this study include the recognition that a reversible component of lung stiffening may occur in anaesthetized or relaxed patients undergoing management with positive end-expiratory pressure, even though lung volume may be improved. In addition, it is clear that "volume history" of lung is an important consideration in the proper interpretation of any measurements of lung mechanics made in this circumstance.

\section{SUMMARY}

We studied supine anaesthetized dogs to determine whether the use of positive end-expiratory pressure to increase functional residual capacity (FRC) could thereby prevent the small lung compliance values frequently reported during anaesthesia. We first made control measurements of FRC and of both static $\left(\mathrm{C}_{\mathrm{STAT}_{\mathrm{T}}}\right)$ and dynamic $\left(\mathrm{C}_{\mathrm{DY} \Psi}\right)$ lung compliance. Continuous positive pressure ventilation (CPPV) with $5 \mathrm{~cm} \mathrm{H} \mathrm{H}_{2} \mathrm{O}$ positive end-expiratory pressure was then commenced, and FRC and compliance measurements were repeated at 15-minute intervals during one hour of CPPV. We found that the positive end-expiratory pressure served to increase FRC to a level expected for unanaesthetized normally breathing dogs in the same posture (J. Appl. Physiol. 36: 93, 1974), and this FRC was well maintained during the one-hour observation period. Despite the volume preservation, we found a marked decline in lung compliance, equal in both $\mathrm{C}_{\text {STAT }}$ and $\mathrm{C}_{\mathrm{DYX}}$; however, these changes were completely reversed to control values following hyperinflation of lung(artificial sighing). We conclude that diminution in lung compliance in our anaesthetized dogs was not dependent on 
low lung volume breathing but must have been due to another mechanism such as suppression of sighing or possibly regional hypoventilation. It might well be important to recognize that reversible reduction of compliance may occur despite increase of FRC in patients managed with positive end-expiratory pressure.

\section{RÉSUMÉ}

L'objectif de notre recherche, effectuée sur des chiens anesthésiés, était de déterminer si l'augmentation de la capacité résiduelle fonctionnelle, causée par l'emploi d'une Peep, permettait de prévenir la diminuation de compliance pulmonaire secondaire à l'anesthésie.

Dans un premier temps, nous avons établi les valeurs de contrôle en mesurant les capacités résiduelles fonctionnelles, ainsi que les compliances statiques et dynamiques. Puis, ces mesures ont été reprises aux quinze minutes, alors que l'animal était sous Peep à $5 \mathrm{~cm} \mathrm{H}_{2} \mathrm{O}$, et ceci pour une durée d'une heure.

Nos résultats démontrent que l'addition de Peep permet d'augmenter la capacité résiduelle fonctionnelle au niveau normalement trouvé chez des animaux, dans la même posture, respirant normalement, sans anesthésie; cette augmentation se maintenait pendant l'heure que durait la procédure.

Nous avons malgré tout observé une diminution marquée des compliances dynamiques et statiques. Cependant, l'usage de soupirs permettait de ramener ces résultats à la normale.

Nous concluons que la diminution de la compliance observée chez nos chiens n'était pas secondaire à une ventilation superficielle, mais plutôt à un autre mécanisme comme la suppression des soupirs physiologiques, ou peut-être une hypoventilation régionale. Il peut être important de savoir qu'une chute réversible de la compliance peut survenir chez des malades sous Peep.

\section{ACKNOWLEDGMENTS}

This work was supported in part by a grant from the Ontario Thoracic Society. The authors thank Miss P.Y. Chong for valuable technical assistance.

\section{REFERENCES}

1. Bendixen, H.H., Hedley-Whyte, J.E., \& LAver, M.B. Impaired oxygenation in surgical patients during general anaesthesia with controlled ventilation. New Eng. J. Med. 269: $991(1963)$.

2. Douglas, F.G., Cocco, J., Brinde, F., et al. Pulmonary mechanics and gas exchange during neurological anaesthesia. Can. Anaesthetists Soc. J. 16: 7 (1969).

3. Gold, M.I. \& Helrich, M. Pulmonary compliance during anesthesia. Anesthesiology 26: $281(1965)$.

4. MEAD, J, \& COLlien, C.R. Relation of volume history of lung to respiratory mechanics in anesthetized dogs. J. Appl. Physiol. 14: 669 (1959).

5. Westbrook, P.R., Stubbs, S.E., Sessler, A.S., Rehder, K., \& Hyatt, R.E. Effects of anesthesia and muscle paralysis on respiratory mechanics in normal man. J. Appl. Physiol. 34: 81 (1973). 
6. Caro, C.D., BUtleh, J., \& DUBoIs, A.B. Some effects of restriction of chest cage expansion on pulmonary function in man: an experimental study. J. Clin. Invest. 39: (1960).

7. Douglas, F.G., Chong, P.Y., \& Finlayson, D.C. Effect of artificial ventilation on lung mechanics in dogs. J. Appl. Physiol. 37: 324 (1974).

8. DuBors, A.B., Botelho, S.Y., Bedell, G.N., Mahshall, R., \& Compoe, J.H. A rapid plethysmographic method for measuring thoracic gas volume. J. Clin. Invest. 35: 322 (1956).

9. Feigl, E.O. \& D'Alecy, L.G. Normal arterial blood pH, oxygen and carbon dioxide tensions in unanesthetized dogs. J. Appl. Physiol. 32: (1972).

10. McIntyre, R.W., Laws, A.K., \& Ramachandran, P.R. Positive expiratory pressure plateau: improved gas exchange during mechanical ventilation. Can. Anaesthetists Soc. J. 16: 477 (1969).

11. Gillespie, D.J. \& Hyatr, R.E. Respiratory mechanics in the unanesthetized dog. J. Appl. Physiol. 36: 93 (1974).

12. Otrs, A.B., McKerrow, C.B., Bartletr, R.A., Mead, J., McIlnoy, M.D., Selverstone, N.J., \& Radfond, E.P. Mechanical factors in distribution of pulmonary ventilation. J. Appl. Physiol. 8: 427 (1956).

13. RadFord, E.P. Static mechanical properties of lungs. Chapt. 15 in Handbook of Physiology: Respiration I. Washington, American Physiological Society (1964).

14. Froese, A.B. \& Bryan, A.C. Effects of anesthesia and paralysis on diaphragmatic mechanics in man. Anesthesiology. 41: 242 (1974). 